\title{
Author Correction: Isolated detection of elastic waves driven by the momentum of light
}

\author{
Tomaž Požar (10 1, Jernej Laloš', Aleš Babnik¹, Rok Petkovšek1, Max Bethune-Waddell², Kenneth J. Chau², \\ Gustavo V.B. Lukasievicz (1) ${ }^{3}$ \& Nelson G.C. Astrath (i) ${ }^{4}$
}

Correction to: Nature Communications https://doi.org/10.1038/s41467-018-05706-3, published online 21 August 2018.

The original version of this Article contained an error in the $x$-axis labels of Fig. $3 \mathrm{a}$, b, which incorrectly read ' $z$ (mm)'. The correct version states ' $z(\mathrm{~nm})$ '. This has been corrected in both the PDF and HTML versions of the Article.

Published online: 28 August 2019

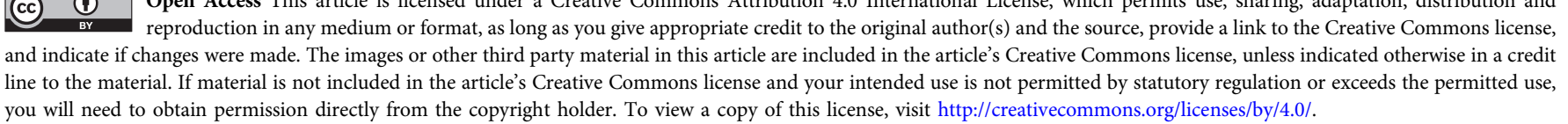

(C) The Author(s) 2019

\footnotetext{
${ }^{1}$ Faculty of Mechanical Engineering, University of Ljubljana, Ljubljana 1000, Slovenia. ${ }^{2}$ School of Engineering, The University of British Columbia, Kelowna, BC V1V-1V7, Canada. ${ }^{3}$ Department of Physics, Universidade Tecnológica Federal do Paraná, Medianeira, Paraná 85884-000, Brazil. ${ }^{4}$ Department of Physics, Universidade Estadual de Maringá, Maringá, Paraná 87020-900, Brazil. Correspondence and requests for materials should be addressed to T.P.

(email: tomaz.pozar@fs.uni-lj.si) or to N.G.C.A. (email: ngcastrath@uem.br)
} 